\title{
PENGARUH KUALITAS LAYANAN ATAS KEPUASAN SISWA DAN DAMPAKNYA TERHADAP LOYALITAS SISWA DI SMK KRISTEN SALATIGA
}

\author{
Noventris Ratnawati Radja \\ Alumni Magister Manajemen Pendidikan Universitas Kristen Satya Wacana \\ Supramono \\ Magister Manajemen Pendidikan Universitas Kristen Satya Wacana \\ supramono@staff.uksw.edu \\ Bambang Suteng Sulasmono \\ Magister Manajemen Pendidikan Universitas Kristen Satya Wacana \\ bambang.sulasmono@staff.uksw.edu
}

\begin{abstract}
School as a public Education institute must serve good quality education especially for the students, so that the students will feel satisfied to the service and show their loyal attitude toward the school. This study was done at SMK Kristen Salatiga to identify the effect of the service quality with student's satisfaction and its effect to the student's loyalty toward the school. The sample of this study was 100 students of SMK Kristen Salatiga grade II and III out of 261 populations. The result of the study showed that; (1) The quality service at SMK Kristen Salatiga have a positive impact and significant to the SMK Kristen Salatiga student's satisfaction. (2) The student's satisfaction have a positive influence and significant to their loyalty. (3) There is no correlation between the service quality and the student's loyalty at SMK Kristen Salatiga toward the student's satisfaction variable. (4) The quality service at SMK Kristen Salatiga directly effect and not significant to the student's loyalty.
\end{abstract}

Keywords: Service quality, consumer satisfactory, consumer loyalty

\section{PENDAHULUAN}

Pengembangan siswa dapat dilakukan melalui aktivitas siswa dan proses pembelajaran di sekolah, untuk itu perlu diperhatikan faktor-faktor yang dapat mendukung proses pembelajaran, agar dapat memberikan layanan yang berkualitas bagi siswa. Layanan yang seharusnya diberikan sekolah bagi siswanya yaitu fasilitas belajar yang menunjang aktivitas siswa di sekolah, kurikulum dan administrasi sekolah yang teratur. Fasilitas belajar adalah segala sesuatu yang dapat menunjang dan mempermudah kegiatan belajar mengajar. Fasilitas belajar diidentikkan dengan sarana prasarana pendidikan, Prantiya (2008). Fasilitas yang dimaksud adalah sarana dan prasarana pendidikan yang ada di sekolah berupa, gedung atau ruang kelas dan perabot serta peralatan pendukung di dalamnya, media pembelajaran, buku atau sumber belajar lainnya. Selain itu diperlukan juga tenaga pengajar yang berkompeten pada bidangnya, bahan, metode dan media ajar yang mendukung serta tepat bagi siswa. Hal lainnya yang tak kalah penting adalah layanan administrasi yang jelas, baik bagi siswa maupun orang tua, keamanan lingkungan sekolah, pengelolaan waktu, pengadaan organisasi dan ekstrakurikuler yang bermanfaat bagi siswa. 
Bentuk layanan yang diberikan sekolah kepada siswa perlu diterapkan seperti yang telah dijelaskan di atas. Jika layanan pendidikan yang diberikan sekolah memuaskan dan dapat diterima dengan baik oleh para siswa, maka dengan sendirinya siswa akan menunjukkan sikap yang loyal terhadap sekolah. Jones dan Sanser dalam Hurriyati (2005) yang mempelajari persiapan penerapan berbagai kesempatan perdagangan di era globalisasi, berpendapat bahwa yang menjadi tumpuan perusahaan untuk tetap mampu bertahan hidup adalah pelanggan-pelanggan yang loyal. Perusahaan dituntut agar mampu memupuk keunggulan kompetitifnya masing-masing melalui upaya-upaya yang kreatif, inovatif serta efisien. Demikian halnya dengan instansi sekolah, yang seharusnya selalu mengembangkan kreativitas dan efisiensi dalam layanan terhadap siswa.

Beberapa tahun terakhir, dalam upaya menjalankan misi dan tujuannya berupa layanan pendidikan, SMK Kristen Salatiga mengalami peningkatan dan penurunan jumlah siswa. Dari data yang diperoleh, menunjukkan adanya peningkatan dan penurunan dari segi jumlah siswa secara keseluruhan (kelas 1- kelas 3) sejak tahun 2007 sampai 2012. Demikian pula yang terjadi dengan jumlah siswa yang masuk pada kelas 1 di SMK Kristen Salatiga.

Sejak tahun 2007, jumlah siswa mengalami penurunan hingga tahun 2009, dari total 489 siswa hingga menjadi 467 siswa. Pada tahun 2010 mengalami peningkatan yang bagus (501 siswa), kemudian di tahun 2012 terjadi penurunan jumlah siswa menjadi 377 siswa. Demikian pula dengan jumlah siswa yang masuk pada setiap tahun ajaran baru di SMK Kristen Salatiga, tidak selalu meningkat. Pada tahun 2009-2010 mengalami peningkatan, sedangkan pada tahun 2012 mengalami penurunan yang signifikan.

Dari data tentang penurunan jumlah siswa yang masuk pada tahun 2012 di SMK
Kristen Salatiga, menimbulkan pertanyaan, yaitu apa yang menyebabkan terjadinya penurunan jumlah siswa pada tahun 2012? Apakah layanan yang diberikan kepada siswa belum sesuai dengan harapan, sehingga menyebabkan ketidakpuasan dan berpengaruh pada sikap loyalitas siswa?

Kepuasan konsumen, yaitu siswa dan orang tua sangat penting karena memberikan manfaat bagi sekolah yaitu dapat menimbulkan loyalitas konsumen. Meningkatkan kualitas layanan pendidikan dalam upaya memelihara loyalitas siswa merupakan tuntutan yang harus selalu dilaksanakan. Siswa dan orang tua yang loyal terhadap sekolahnya akan memanfaatkan ulang jasa pendidikan yang telah dirasakannya dan juga dapat memberikan rekomendasi kepada orang-orang terdekat mereka untuk menjadi siswa di SMK Kristen Salatiga.

Berdasarkan latar belakang yang dipaparkan, penelitian ini bertujuan untuk: (1) menguji pengaruh kualitas layanan yang diberikan SMK Kristen Salatiga terhadap kepuasan siswa. (2) menguji pengaruh kepuasan siswa terhadap loyalitas siswa di SMK Kristen Salatiga. (3) menguji pengaruh kualitas layanan yang diberikan SMK Kristen Salatiga terhadap loyalitas siswa.

\section{TINJAUAN PUSTAKA}

Kualitas layanan dapat diartikan sebagai upaya pemenuhan kebutuhan dan keinginan konsumen serta ketepatan penyampaiannya dalam mengimbangi harapan konsumen (Tjiptono, 2007). Parasuraman dan kawankawan (1994), mengemukakan lima dimensi pokok kualitas layanan, yaitu: (1) Tangibles (bukti terukur), menggambarkan fasilitas fisik, perlengkapan, dan tampilan dari personalia serta kehadiran para pengguna. (2) Reliability (keandalan), merujuk kepada kemampuan untuk memberikan layanan yang dijanjikan secara akurat dan handal. (3) Responsiveness (daya tanggap), yaitu kesediaan untuk 
membantu pelanggan serta memberikan perhatian yang tepat. (4) Assurance (jaminan), merupakan karyawan yang sopan dan berpengetahuan luas yang memberikan rasa percaya serta keyakinan. (5) Empathy (empati), mencakup kepedulian serta perhatian individual kepada para pengguna.

Menurut Kotler (2000) dan Supranto (2001), kepuasan konsumen adalah perasaan seseorang yang puas atau sebaliknya setelah membandingkan antara kenyataan dan harapan yang diterima dari sebuah produk barang atau jasa. Jadi tingkat kepuasan merupakan fungsi dari perbedaan antara kenyataan dengan harapan.

Gremler dan Brown dalam Hasan (2008) berpendapat bahwa loyalitas adalah pelanggan yang tidak hanya membeli ulang suatu barang dan jasa, tetapi juga mempunyai komitmen dan sikap yang positif terhadap perusahaan jasa, misalnya dengan merekomendasikan orang lain untuk membeli. Menurut Kotler dan Armstong (2008), bahwa loyalitas berasal dari pemenuhan harapan atau harapan konsumen, sedangkan ekspektasi sendiri berasal dari pengalaman pembelian terdahulu oleh konsumen, opini dari teman dan kerabat, janji atau informasi dari pemasar atau pesaing.

Sekolah berkualitas sangat erat hubungannya dengan pemberian pelayanan pendidikan yang bermutu, dan untuk mengetahui tingkat ketercapaian kualitas itu, maka sekolah berkualitas harus merujuk kepada PP No. 19 Tahun 2005 tentang Standar Nasional Pendidikan di Indonesia meliputi: 1) standar isi, 2) standar kompetensi lulusan, 3) standar proses, 4) standar sarana dan prasarana, 5) Standar pengelolaan, 6) Standar pendidik dan tenaga kependidikan, 7) standar pembiayaan, dan 8) standar penilaian (Depdiknas, 2006). Tercapainya kualitas dari kedelapan standar itu kemudian berujung kepada layanan pendidikan kepada peserta didik dan masyarakat serta stakeholder pendidikan sebagai bagian dari konsumen pendidikan.

\section{METODE}

Populasi dalam penelitian ini adalah semua siswa kelas II dan III SMK Kristen Salatiga tahun ajaran 2012/2013, sebanyak sepuluh kelas. Pengambilan sampel penelitian ini menggunakan teknik purposive sampling. Sampel dipilih dari populasi yaitu siswa kelas II dan III SMK Kristen Salatiga, berjumlah 100 siswa.

Penelitian ini mempunyai tiga variabel, yaitu variabel kualitas layanan, variabel kepuasan konsumen dan variabel loyalitas konsumen. Dalam pengukuran variabel kualitas layanan memakai lima dimensi yaitu tangiable, reliability, responsiveness, assurance dan empathy. Kelima dimensi ini menggunakan instrumen berdasarkan kuisioner Cronin dan Taylor (1992) dalam Matabei (2008). Dalam penyusunan instrumen dilakukan penyesuaian dan instrumen ini terdiri dari 47 item pertanyaan. Sedangkan variabel loyalitas konsumen diukur dengan menggunakan instrumen yang terdiri dari enam item pertanyaan berdasarkan konseptualisasi mengenai service loyalty oleh Gemler dan Brown (1996) dalam Aryani \& Rosinta (2010).

\section{HASIL PENELITIAN DAN PEMBAHASAN}

Gambaran secara kuantitatif tentang jawaban responden terhadap variabel yang digunakan dalam penelitian ini, terdapat dalam perhitungan nilai rata-rata skor terhadap setiap item pertanyaan dalam kuisioner.

Pada tabel 1, dapat dilihat gap atau selisih antara kenyataan dan harapan siswa terhadap kualitas layanan yang diberikan SMK Kristen Salatiga untuk semua item dalam kuisioner adalah negatif. Hal ini berarti bahwa semua layanan yang diterima responden dinilai belum memuaskan, karena harapan siswa lebih tinggi dari pada persepsi siswa atau tanggapan siswa terhadap layanan yang telah mereka dapatkan dari pihak sekolah. 


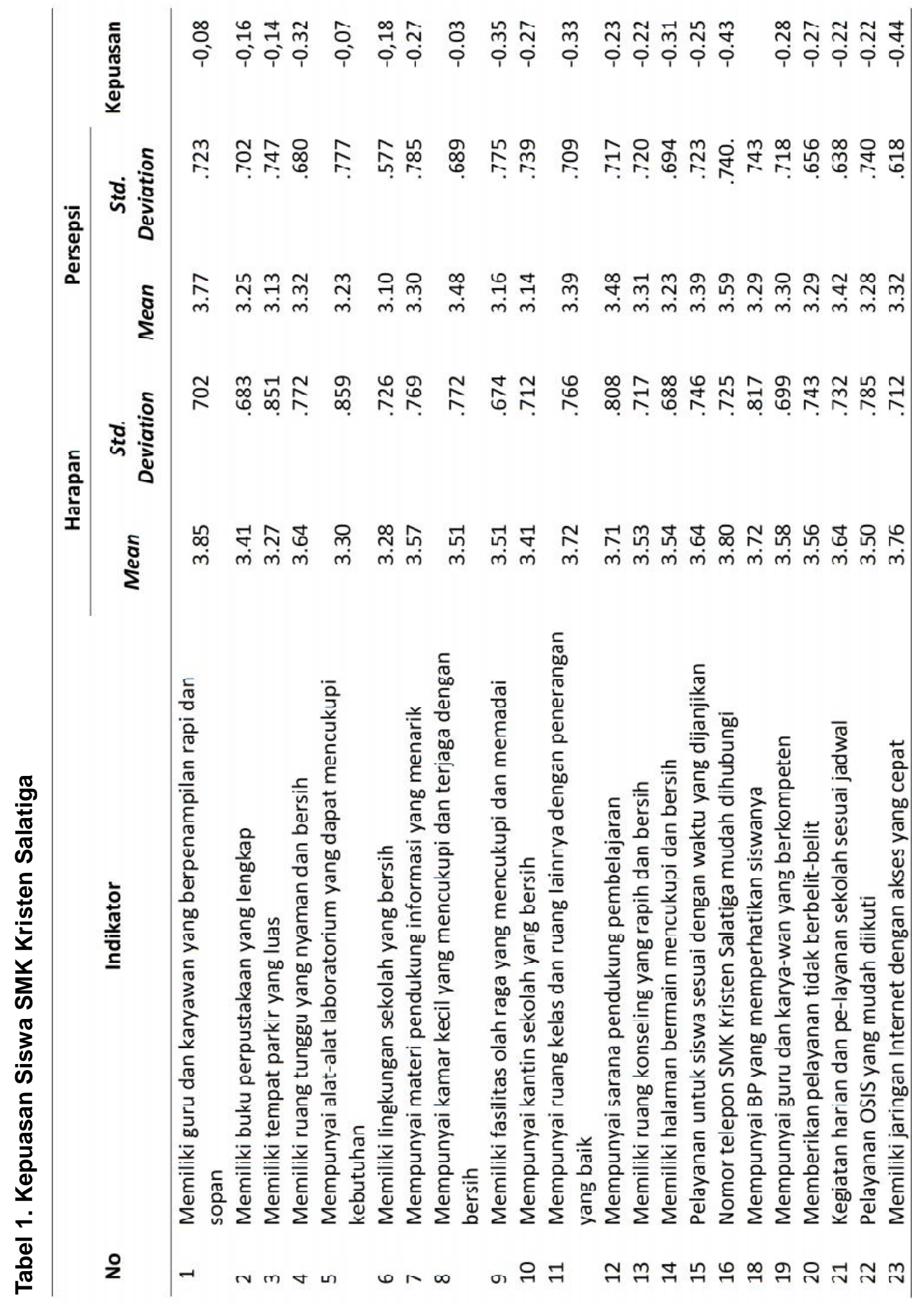


Pengaruh kualitas layanan atas kepuasan siswa dan dampaknya terhadap loyalitas siswa... (Noventris Ratnawati Raja, dkk.)

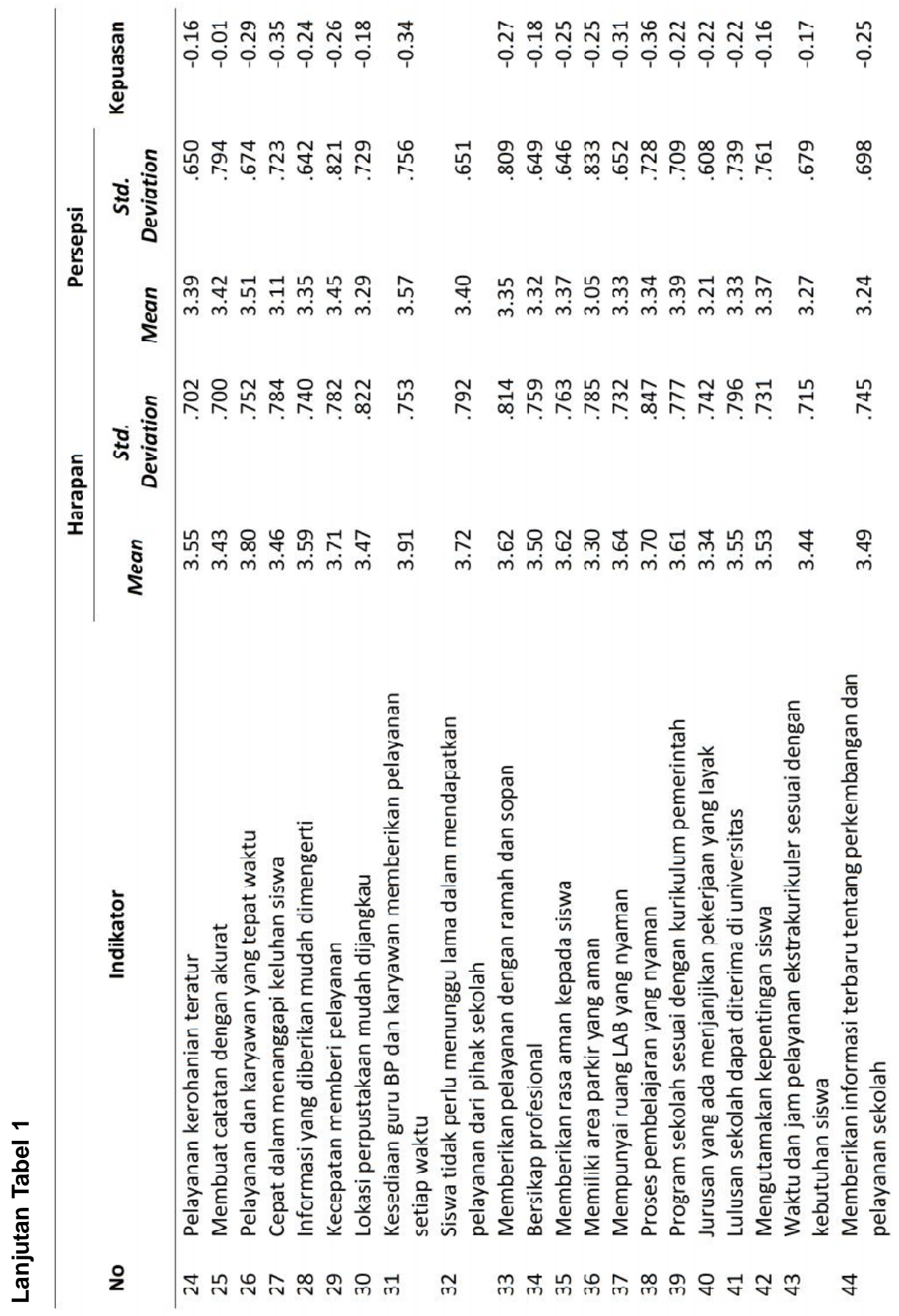


Satya Widya, Vol. 29, No.2, Desember 2013: 83-92

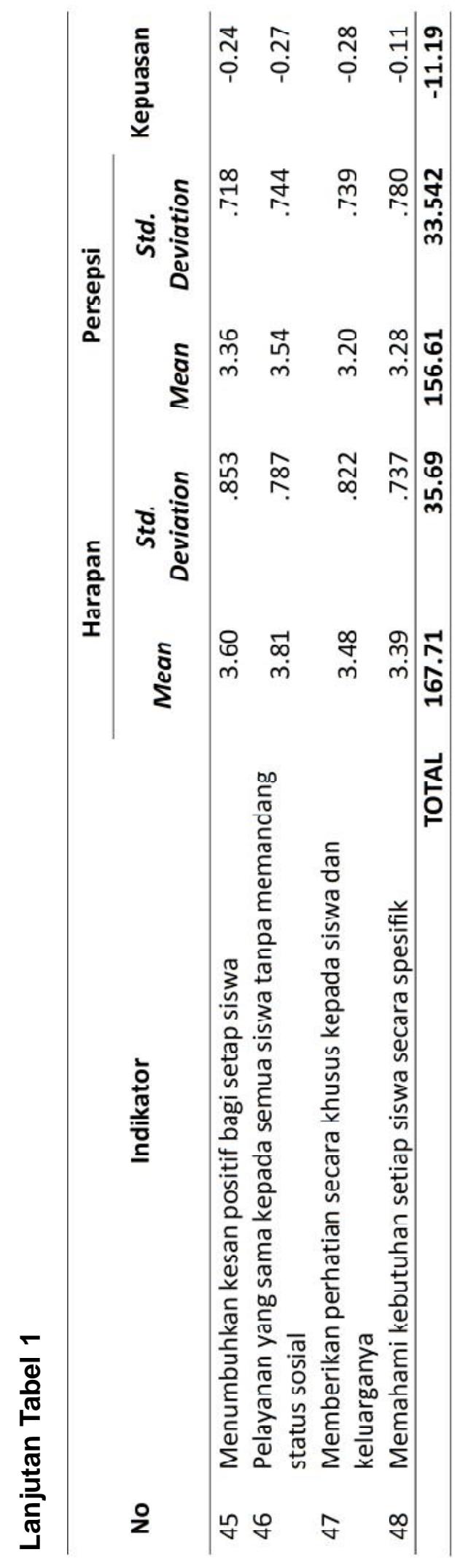


Selisih atau gap antara harapan dan persepsi siswa yang tertinggi adalah ketidakpuasan terhadap jaringan dan penggunaan internet sekolah, yaitu sebesar -0,44. Dari data tersebut menunjukkan bahwa siswa belum merasa puas karena penggunaan internet di sekolah terbatas. Khususnya jika pada saat tertentu guru berhalangan masuk dan tidak ada mata pelajaran pengganti, siswa sebaiknya diberi tugas yang berkaitan dengan mata pelajaran dan dapat menggunakan akses internet yang tersedia, selain pemanfaatan buku di perpustakaan. Di samping itu bisa menciptakan suasana belajar yang nyaman bagi kelas yang sedang melakukan proses belajar mengajar.

Siswa juga merasa tidak puas dengan ruangan laboratorium yang ada. Pada item ini, selisih antara harapan dan persepsi siswa adalah $-0,31$. Penerangan dalam ruangan laboratorium masih kurang, khususnya lab komputer, lab bahasa dan ruang praktik mengetik. Ruangan laboratorium dibuat tertutup agar siswa yang melakukan praktik tidak terganggu dengan kondisi di luar ruangan. Karena itu siswa merasa belum puas dengan penerangan dan sirkulasi udara dalam ruangan laboratorium.
Dari tabel 2 terlihat mean tertinggi adalah 3,80 yaitu adanya kesediaan siswa untuk mempromosikan SMK Kristen Salatiga kepada keluarga, saudara dan teman-teman yang lain. Dengan demikian dapat dikatakan bahwa loyalitas siswa SMK Kristen Salatiga dengan ingin mempromosikan sekolahnya kepada pihak lain dalam hal ini keluarga dan teman atau kenalan, termasuk dalam kategori tinggi. Sedangkan mean loyalitas terendah yaitu 3,47, keyakinan bahwa siswa tidak ingin pidah dari SMK Kristen Salatiga sampai ia lulus. Artinya masih ada kemungkinan bahwa siswa dapat beralih atau pindah ke instansi atau sekolah yang lain dengan berbagai alasan. Tetapi nilai rata-rata dalam loyalitas ini masih termasuk pada kategori tinggi.

\section{Hasil Uji Hipotesis}

Setelah melakukan analisis hasil uji asumsi klasik melalui uji normalitas, uji heterokedasitas, dan uji autokorelasi, selanjutnya dilakukan analisis hasil uji hipotesis pertama sampai hasil uji hipotesis keempat. Analsis pengujian hipotesis pertama, menggunakan teknik analisis regresi sederhana dan output yang dihasilkan menunjukkan Beta sebesar 0,693, artinya ada pengaruh positif kualitas

Tabel 2. Loyalitas Siswa SMK Kristen Salatiga

\begin{tabular}{|c|c|c|c|}
\hline No & Indikator & Mean & $\begin{array}{c}\text { Std. } \\
\text { Deviation }\end{array}$ \\
\hline 1 & $\begin{array}{l}\text { Bersedia memberikan rekomendasi kepada teman atau } \\
\text { kenalan }\end{array}$ & 3.71 & 659 \\
\hline 2 & $\begin{array}{l}\text { Mendorong teman dan kenalan untuk sekolah pada institusi } \\
\text { yang sama }\end{array}$ & 3.61 & .712 \\
\hline 3 & $\begin{array}{l}\text { Tidak pernah berpikir untuk ganti atau beralih studi ke } \\
\text { institusi lain }\end{array}$ & 3.47 & .812 \\
\hline 4 & Yakin bahwa tempat studi adalah jelas terbaik & 3.57 & .745 \\
\hline 5 & $\begin{array}{l}\text { Bersedia menceritakan hal-hal positif tentang institusi } \\
\text { (sekolah) }\end{array}$ & 3.76 & .797 \\
\hline \multirow[t]{2}{*}{6} & Bersedia mempromosikan Sekolah pada keluarga atau teman & 3.80 & .795 \\
\hline & Total & 21,92 & 3,14 \\
\hline
\end{tabular}

Sumber: Data primer yang diolah, 2013 
layanan terhadap kepuasan konsumen. Angka $\mathrm{R}^{2} 0,36$ berarti ada 36 persen kepuasan konsumen yang dijelaskan oleh kualitas layanan. Pada tingkat signifikansi 5 persen nilai $\mathrm{t}$ hitung 9,524 > t tabel 1,663 dan dilihat dari propabilitas $0,00<0,05$, maka koefisien regresi dikatakan signifikan. Jadi $\mathrm{H}_{1} 1$ diterima, artinya tingkat kualitas layanan berpengaruh positif dan signifikan terhadap kepuasan konsumen. Hal ini sejalan dengan hasil penelitian dari Abadi (2005), Rahayu (2008), Matabei (2008), Prasetyaningrum (2009) dan Susanti (2011).

Hasil analisis uji hipotesis kedua menunjukkan Beta sebesar 0,658, artinya ada pengaruh positif kepuasan konsumen terhadap loyalitas konsumen. Angka R 20,10 berarti ada 10 persen loyalitas konsumen yang dijelaskan oleh kepuasan konsumen. Pada tingkat signifikansi 5 persen nilai t hitung 8,654 >t tabel 1,663 dan dilihat dari propabilitas 0,00 $<0,05$, maka koefisien regresi dikatakan signifikan. Jadi $\mathrm{H}_{1} 2$ diterima, artinya tingkat kepuasan konsumen berpengaruh positif terhadap loyalitas konsumen. Hasil penelitian ini sejalan dengan hasil penelelitian Abadi (2005), Rahayu (2008), Prasetyaningrum (2009) dan Susanti (2011), yang menyatakan bahwa kepuasan konsumen berpengaruh positif dan signifikan terhadap loyalitas konsumen. Keempat hasil penelitian tersebut tidak sejalan dengan hasil penelitian Matabei (2008), yang menyatakan bahwa kepuasan konsumen tidak berpengaruh positif dan signifikan dengan loyalitas konsumen.

Hipotesis ketiga diuji dengan mendeteksi pengaruh kualitas layanan terhadap loyalitas konsumen melalui mediasi variabel kepuasan konsumen. Koefisien dihitung dengan membuat dua persamaan struktural yaitu persamaan regresi yang menunjukan hubungan yang dihipotesiskan sebagai berikut:
(1) $Y_{1}=\mathrm{a}+\mathrm{b} X$
(2) $Y_{2}=a+b X+b$

Dalam perhitungan pengaruh mediasi, diperoleh $\mathrm{t}$ hitung 0.618 dengan tingkat signifikansi 5 persen. Pada tingkat signifikansi 5 persen, nilai t hitung $0.618<\mathrm{t}$ tabel 1,663 , dengan koefisien mediasi 0.078 , sehingga dapat dikatakan bahwa tidak terjadi pengaruh mediasi. Jadi $\mathrm{H}_{1} 3$ ditolak, artinya tingkat kualitas layanan melalui mediasi variabel kepuasan konsumen tidak berpengaruh secara signifikan terhadap loyalitas konsumen. Hasil penelitian ini tidak sejalan dengan hasil penelitian Murjoko dan Shihab (2011), yang menyatakan bahwa kualitas layanan melalui mediasi kepuasan siswa berpengaruh secara signifikan terhadap loyalitas siswa.

Pada output hasil analisis uji hipotesis keempat menunjukkan Beta sebesar 0,115 yang menyatakan adaya pengaruh positif kualitas layanan terhadap loyalitas konsumen. Angka $\mathrm{R}^{2} 0,02$ berarti ada 2 persen loyalitas konsumen yang dijelaskan oleh kualitas layanan. Pada tingkat signifikansi 5 persen nilai t hitung 0,823 $<\mathrm{t}$ tabel 1,663 dan dikihat dari propabilitas $0,044<0,05$, maka koefisien regresi dikatakan tidak signifikan. Jadi $\mathrm{H}_{1} 4$ ditolak, artinya tingkat kualitas layanan tidak berpengaruh secara signifikan terhadap loyalitas konsumen. Hal ini tidak sejalan dengan hasil penelitian Noviana (2007) yang menyatakan bahwa kualitas layanan secara parsial dan simultan berpengaruh secara signifikan terhadap loyalitas konsumen. Penelitian ini sejalan dengan hasil penelitian Wantara (2009), yang menyatakan bahwa kualitas layanan berpengaruh positif, tetapi tidak signifikan terhadap loyalitas mahasiswa.

\section{KESIMPULAN}

Berdasarkan hasil analisis, maka ditarik kesimpulan sebagai berikut:

1. Berpengaruh positif dan signifikan terhadap kepuasan siswa SMK Kristen Salatiga. Hal ini berarti bahwa semakin tinggi kualitas layanan yang diberikan, maka semakin 
Pengaruh kualitas layanan atas kepuasan siswa dan dampaknya terhadap loyalitas siswa... (Noventris Ratnawati Raja, dkk.)

tinggi pula kepuasan yang dirasakan oleh konsumen.

2. Kepuasan siswa berpengaruh positif dan signifikan terhadap loyalitas siswa kepada SMK Kristen Salatiga. Artinya semakin tinggi kualitas layanan yang diberikan dapat mempengaruhi kepuasan siswa, sehingga menimbulkan sikap loyal kepada SMK Kristen Salatiga.

3. Hasil perhitungan variabel intervening dengan sobel test menunjukkan bahwa tidak ada pengaruh kualitas layanan SMK Kristen Salatiga terhadap loyalitas siswa melalui mediasi dengan variabel kepuasan siswa SMK Kristen Salatiga.

4. Kualitas layanan tidak berpengaruh secara langsung dan tidak signifikan terhadap loyalitas konsumen. Jadi peningkatan kualitas layanan yang diberikan SMK Kristen Salatiga, tidak secara langsung dapat meningkatkan loyalitas siswa.

\section{DAFTAR PUSTAKA}

Hasan, Ali. 2008. Marketing. Jakarta: PT Buku Kita.

Aryani Dwi \& Rosinta F. 2010. Pengaruh Kualitas Layanan terhadap Kepuasan Pelanggan dalam Membentuk Loyalitas Pelanggan. Bisnis \& Birokrasi. Jurnal Ilmu Administrasi dan Organisasi Vol.17, No.2.

Haryanti, K. 1999. Hubungan Persepsi Mutu Pelayanan dan Nilai Konsumen dengan Kepuasan Konsumen. Yogyakarta: Tesis, PPS-UGM.

Hurriyati, Ratih. 2005. Bauran Pemasaran dan Loyalitas Konsumen. Cetakan Pertama, Bandung: CV. ALFABETA.

Kotler, Philip dan Gary Armstrong. 2008. Prinsi-Prinsip Pemasaran. Edisi Bahasa Indonesia. Jilid 1. Alih Bahasa: Bob Sabran, M.M. Jakarta: Penerbit Erlangga.
Matabei, Merryl S.S.U. 2008. Analisis Pengaruh Kualitas Pelayanan Terhadap Kepuasan Konsumen dan Dampaknya Terhadap Loyalitas konsumen (Survei Pada Mahasiswa Program Pascasarjana UKSW). Salatiga.

Murjoko, Ridho dan Shihab, Muchsin S. 2011. Pengaruh Kualitas Pelayanan dan Kepuasan Terhadap Loyalitas. Jurnal Manajemen dan Bisnis Sriwijaya Vol.9 No.17 Juni 2011.

Noviana, Dice. 2007. Pengaruh kualitas pelayanan terhadap loyalitas siswa di lembaga bimbingan belajar Sony Sugeme College (SSC) Malang: Jurusan Manajemen Universitas Negeri Malang.

Parasuraman, A., Valarie Zeithaml \& Leonard L. Berry. 1994. Reassessment of Expectations as a Comparison Standard in Measuring Service Quality: Implication for Futher Research. Journal of Marketing, Vol. 52. Pp 111-124

Prasetyaningrum, I.D. 2009. Analisis pengaruh variabel kualitas pembelajaran dan variabel kualitas pelayanan terhadap kepuasan mahasiswa dan loyalitas mahasiswa UNDARIS Ungaran. Program Pascasarjana Magister Manajemen UNDIP, Semarang.

Prantiya. 2008. Kontribusi Fasilitas Belajar dan Motivasi Berprestasi Terhadap Hasil Belajar Kimia pada Siswa SMA Negeri 1 Karangnongko Kabupaten Klaten. Tesis tidak diterbitkan. Surakarta: Program Pascasarjana Universitas Muhammadiyah Surakarta.

Mulyasa, E. 2005. Menjadi Guru Profesional. Bandung: PT. Remaja Rosdakarya.

Rahayu, Y.S. Harsono, O.S.H, \& Suman, A. 2008. Analisis Pengaruh Dimensi Kualitas Jasa Terhadap Kepuasan \& Loyalitas Mahasiswa (Studi pada 
Universitas Swasta di Kota Malang). Lembaga Penelitian Universitas Brawijaya Malang.

Supranto, J. 2001. Pengukuran Tingkat Kepuasan Pelanggan, Jakarta: Rineka Cipta.

Susanti, Serafina Candrika. 2011. Analisis Pengaruh Kualitas Pelayanan Terhadap Kepuasan Mahasiswa Berdampaknya Terhadap Loyalitas Mahasiswa (Studi pada mahasiswa program diploma Fakultas Teknik Universitas Diponegoro). Salatiga: Tesis PPs MMP UKSW.
Wantara, Pribanus. 2009. Pengaruh Citra, Reputasi dan Kualitas Pelayanan Terhadap Kepuasan dan Loyalitas Mahasiswa PTS di Jawa Timur (Studi Pada STIE Dengan Program Studi Terakreditasi). Fakultas Ekonomi Universitas Trunojoyo Bangkalan, Madura. 